\title{
User Guide to the $\alpha$-opic Toolbox for implementing CIE S 026
}

This User Guide relates to the $\alpha$-opic Toolbox v1.049a, published by CIE Division 6.

The Toolbox (DOI 10.25039/S026.2018.TB) and User Guide (DOI 10.25039/S026.2018.UG) are maintained under CIE Division Reportership (DR) 6-45.

Last updated November 2020 


\section{Toolbox - Basis, disclaimer and contact}

The $\alpha$-opic Toolbox and User Guide were designed by the International Commission on Illumination (CIE) to enable calculations and conversions of quantities related to ipRGC-influenced responses to light (IIL responses, or non-visual effects of light), following the international standard CIE S 026:2018. System for Metrology of Optical Radiation for ipRGC-Influenced Responses to Light. CIE, Vienna (DOI: 10.25039/S026.2018).

The $\alpha$-opic Toolbox is a CIE publication(DOI: 10.25039/S026.2018.TB) under the Division 6 Reportership DR 6-45 Publication and maintenance of the CIE S 026 Toolbox. The $\alpha$-opic Toolbox supports the usage of CIE S 026, but is not part of the official international standard. The toolbox was designed with feedback from experts including the participants of the Tutorial on CIE S 026. Use and application of the new metrology for ipRGC-influenced responses to light, 14-15 March 2019, Eindhoven.

No liability is taken by CIE for any potential errors due to calculations with the $\alpha$-opic Toolbox. It is recommended that users check the results against manual calculations. Considered feedback is welcome and should be sent to the Reporter of DR 6-45 via ciecb@cie.co.at who will aim to answer any questions as quickly as possible. 


\section{Toolbox - Author and advisors}

- The following member of DR 6-45 took part in the preparation of the Toolbox and this User Guide

- Price, L.L.A.

Public Health England, United Kingdom

- The following experts acted as advisors:

- Peirson, S.N.

- Schlangen, L.J.M.

- Spitschan, M.

- Lang, D.

- Blattner, P.
University of Oxford, United Kingdom

Eindhoven University of Technology, The Netherlands

University of Oxford, United Kingdom

LEDVANCE, Munich, Germany

METAS, Bern, Switzerland 


\section{Toolbox - Main features}

- Selection of spectral data used for calculations

Built-in illuminants A, D65, E, FL11, and LED-B3 (all: range $380 \mathrm{~nm}$ to $780 \mathrm{~nm}$, step $1 \mathrm{~nm}$ ) (CIE, 2018a); or User-defined spectral data with a choice of wavelength step (1 nm, $2 \mathrm{~nm}, 4 \mathrm{~nm}$ or $5 \mathrm{~nm}$ )

- Choice of basic quantity

Photon radiance, photon irradiance, radiance, irradiance, luminance, illuminance (CIE, 2011; BIPM, 2019) Control of SI prefixes, e.g. $\mathrm{m}$ in $\mathbf{m W} \cdot \mathrm{m}^{-2} \cdot \mathrm{sr}^{-1}, \mu$ and $\mathrm{c}$ in $\mu \mathrm{W} \cdot \mathrm{cm}^{-2}, \mathbf{k}$ in $\mathbf{k l x}, \mathrm{c}$ in $\mathrm{cd} \cdot \mathrm{cm}^{-2}$

- CIE S 026 calculations and conversions (CIE, 2018b)

Basic quantity and additional $\alpha$-opic output quantities are calculated: $\alpha$-opic irradiance, $\alpha$-opic equivalent daylight (D65) illuminance ( $\alpha$-opic EDI), $\alpha$-opic photon irradiance, or their radiance and luminance analogues, as well as the $\alpha$-opic efficacy of luminous radiation ( $\alpha$-opic ELR) 


\section{Toolbox - Additional features}

- Charts and action spectra

The test spectrum and the reference spectrum (default = D65) before and after $\alpha$-opic action spectra weighting

\section{- Glossary}

List of quantities, abbreviations and symbols from CIE S 026 (CIE, 2018b)

\section{- Advanced outputs}

Switch outputs between the quantities from CIE S 026 and the former Lucas et al., 2014 recommendations Displays values for the reference source, matched to the test source inputs Displays $\alpha$-opic Daylight Efficacy Ratio ( $\alpha$-opic DER)

Control of SI prefixes 


\section{Toolbox - Orientation}

Inputs sheet

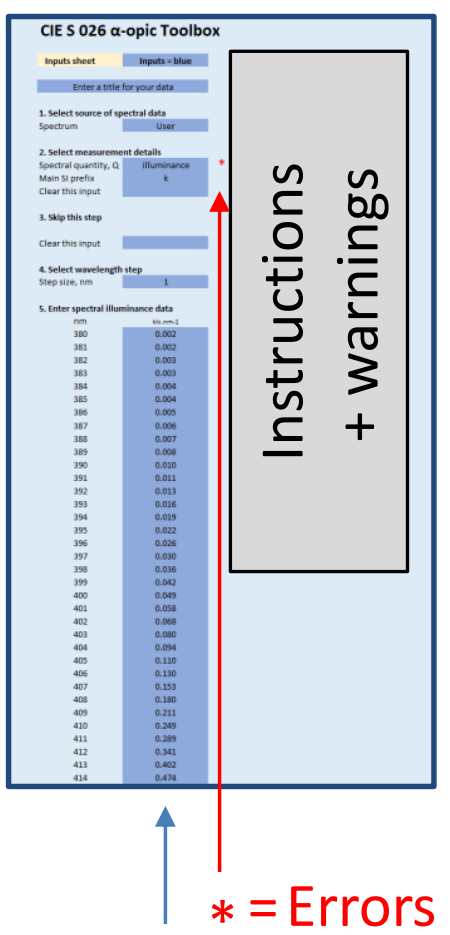

Outputs

CIE S $026 \alpha$-opic Toolbox

outputs

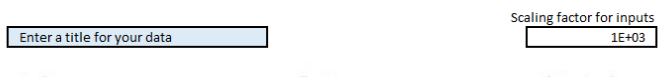

Irradiance
W.m-2

lx

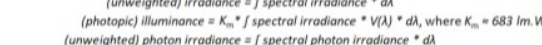

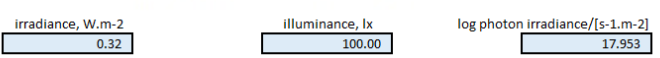
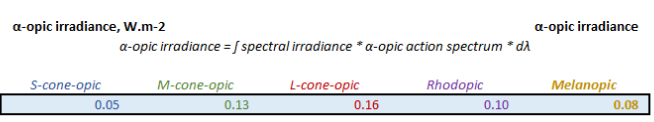

$\alpha$-opic efficacy of luminge

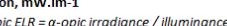

a-opic ERR

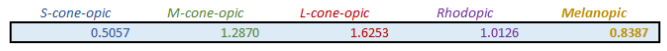

a-opic equivalent daylight (D65) illuminance, Ix

(D)

opic EDI

\begin{tabular}{|lrrrr|} 
S-cone-opic & M-cone-opic & L-cone-opic & Rhodopic & Melanopic \\
\hline 61.88 & 88.40 & 99.78 & 69.85 & 63.24 \\
\hline
\end{tabular}

$\log \alpha$-opic photon irradiance, $\log$ Q/[s-1.m-2] $a$-opic photon irradiance
ucic action spectrum $* d \lambda$

\begin{tabular}{|rrrrr} 
S-cone-opic & M-cone-opic & L-cone-opic & \multicolumn{1}{c}{ Rhodopic } & Melanopic \\
\hline 17.057 & 17.544 & 17.666 & 17.411 & 17.315 \\
\hline
\end{tabular}

$\alpha$-opic photon irradiance in standerd notson

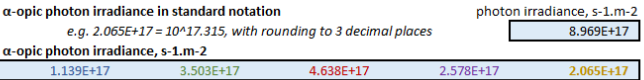

\section{Charts}

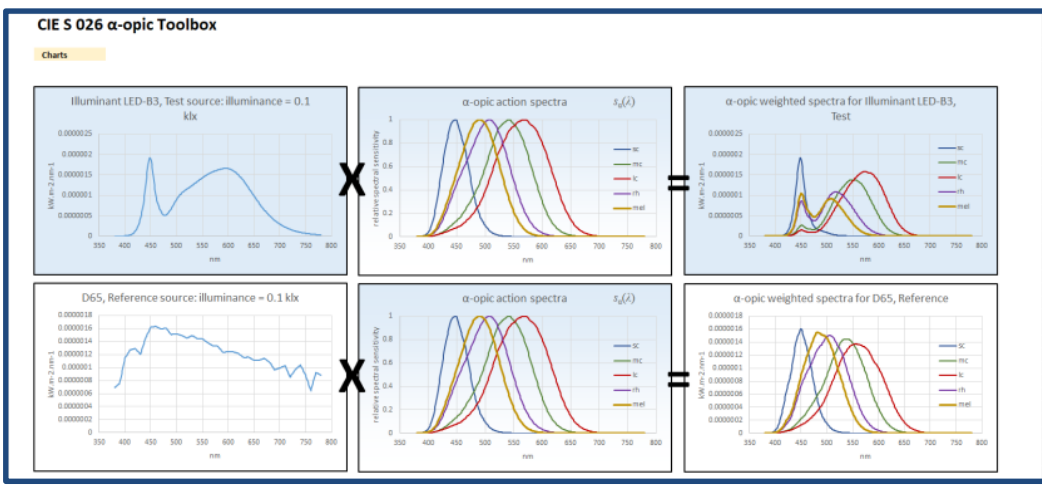

Glossary

Action spectra

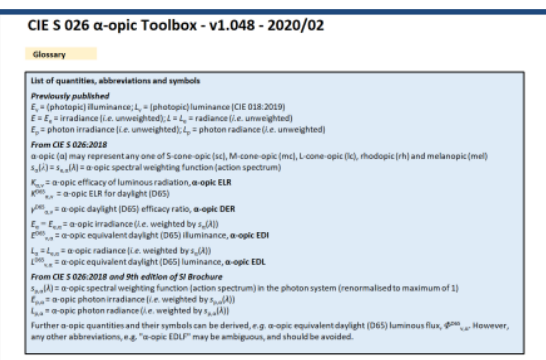

CIE S $026 \alpha$-opic Toolbox

antionsectin

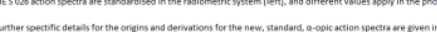

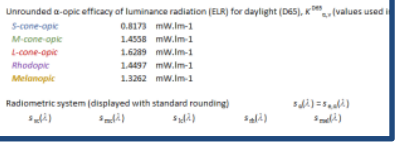

Advanced Outputs

see page 24 


\section{Inputs - Quick calculations}

Example for built-in spectra

First enter a title

< Quick calculation >

\section{Select from list}

(5 CIE illuminants) < LED-B3 >

\section{Select quantity}

(6 options) <illuminance > and units

(SI prefixes) $<$ k $><$ blank $>$

\section{Enter value}

$(0.10 \mathrm{klx}=100 \mathrm{~lx})<0.10>$

Finally clear unused inputs (i.e. manually clear cells C24:C424)

\section{CIE S $026 \alpha$-opic Toolbox}

Inputs sheet

Inputs = blue

\section{Quick calculation}

1. Select source of spectral data Spectrum

LED-B3

LED-B3: Range $380 \mathrm{~nm}$ to $780 \mathrm{~nm}$, step $1 \mathrm{~nm}$

2. Select measurephent details

Quantity, Q

Main SI prefix

Clear this input

3. Enter iyuminance value

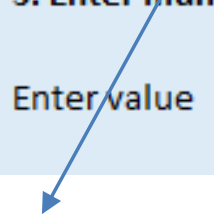




\section{Inputs - Dealing with Error Messages}

- Check whether there is red text under 'Error messages'.

- In case of (red) error messages, follow instructions relating to the input/cell (usually highlighted with a red asterisk).

- If not, please go to the next page of the User Guide (Output Results).

NOTE Use a comma or a dot as your decimal separator based on your Excel settings. 


\section{Outputs - What results are provided?}

\section{Basic quantities}

irradiance, illuminance and log photon irradiance

\section{$\alpha$-opic irradiance}

(in $\mathrm{W} \cdot \mathrm{m}^{-2}$ )

\section{$\alpha$-opic ELR}

efficacy of luminous radiation, (in $\mathrm{mW} . \mathrm{Im}^{-1}$ )

\section{$\alpha$-opic EDI}

equivalent daylight (D65) illuminance, (in Ix)

\section{$\alpha$-opic photon irradiance}

(in $\mathrm{s}^{-1} \cdot \mathrm{m}^{-2}$ )

Each value is presented as the logarithm to base $10\left(\log _{10}\right)$ of the $\alpha$-opic photon irradiance, $Q$, divided by $1 \mathrm{~s}^{-1} \cdot \mathrm{m}^{-2}$

$\left(\log _{10}\right.$ can also be written lg). (unweighted) irradiance $=\int$ spectral irradiance $* d \lambda$

(photopic) illuminance $=K_{\mathrm{m}}{ }^{*} \int$ spectral irradiance $* V(\lambda) * d \lambda$, where $K_{\mathrm{m}} \approx 683 \mathrm{Im} \cdot \mathrm{W}^{-1}$ (unweighted) photon irradiance $=\int$ spectral photon irradiance $* d \lambda$
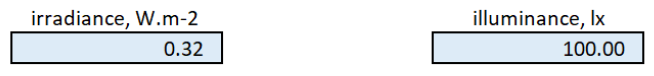

log photon irradiance/(s-1.m-2)

$\alpha$-opic irradiance, $W . m-2$

$\alpha$-opic irradiance $=\int$ spectral irradiance ${ }^{*} \alpha$-opic action spectrum $* d \lambda$

$\alpha$-opic irradiance

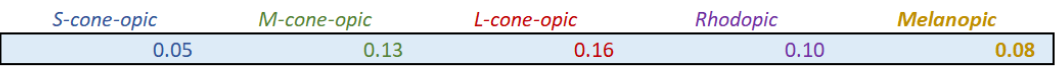

$\alpha$-opic efficacy of luminous radiation, $\mathrm{mW}$.Im-1

$\alpha$-opic ELR

$\alpha$-opic ELR $=\alpha$-opic irradiance $/$ illuminance

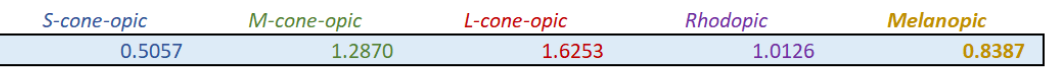

$\alpha$-opic equivalent daylight (D65) illuminance, $\mathrm{Ix}$

$\alpha$-opic EDI

$\alpha$-opic EDI $=\alpha$-opic irradiance $/ \alpha$-opic ELR for daylight (D65)

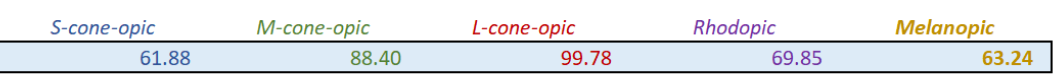

$\log \alpha$-opic photon irradiance, $\log \mathrm{Q} /(\mathrm{s}-1 . \mathrm{m}-2)$, where

$\alpha$-opic photon irradiance $\alpha$-opic photon irradiance $=\int$ spectral photon irradiance * photon system $\alpha$-opic action spectrum *d入

S-cone-opic M-cone-opic L-cone-opic Rhodopic Melanopic 


\section{Outputs - Basic quantities}

\section{irradiance}

(in $\mathrm{W} \cdot \mathrm{m}^{-2}$ )

\section{illuminance}

(in Ix)

\section{photon irradiance}

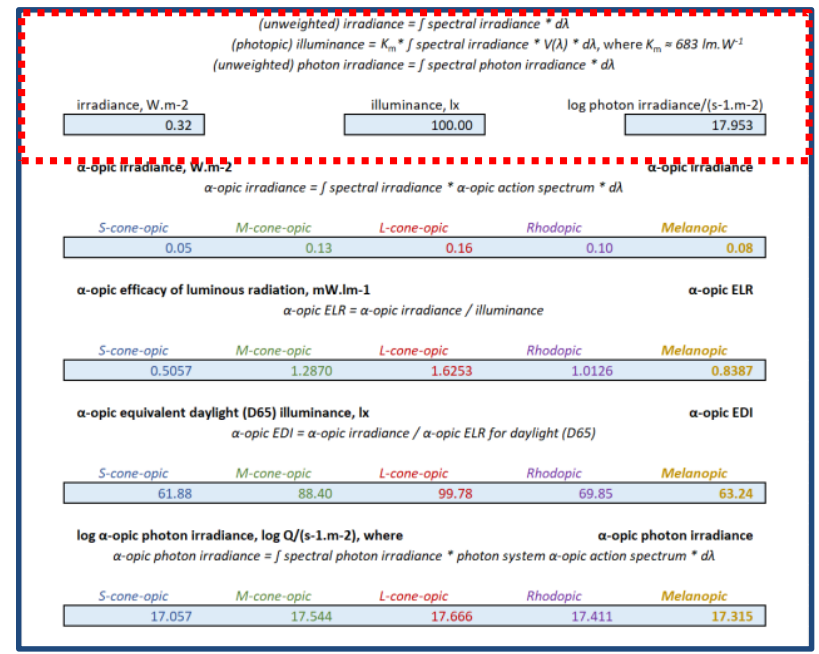

(in $\mathrm{s}^{-1} \cdot \mathrm{m}^{-2}$ and presented as a logarithm)

(unweighted) irradiance $=\int$ spectral irradiance $* d \lambda$

(photopic) illuminance $=K_{\mathrm{m}}{ }^{*} \int$ spectral irradiance ${ }^{*} V(\lambda) * d \lambda$, where $K_{\mathrm{m}} \approx 683 \mathrm{Im} \cdot W^{-1}$

(unweighted) photon irradiance $=\int$ spectral photon irradiance $* d \lambda$

log photon irradiance/(s-1.m-2) 


\section{Outputs - $\alpha$-opic irradiance}

\section{$E_{\alpha}\left(\right.$ in $\left.\mathrm{W} \cdot \mathrm{m}^{-2}\right)$}

"effective photobiological irradiance with the spectral irradiance, $E_{\mathrm{e}, \lambda}(\lambda)$, spectrally weighted with the $\alpha$-opic action spectrum $s_{\alpha}(\lambda)^{\prime \prime}$

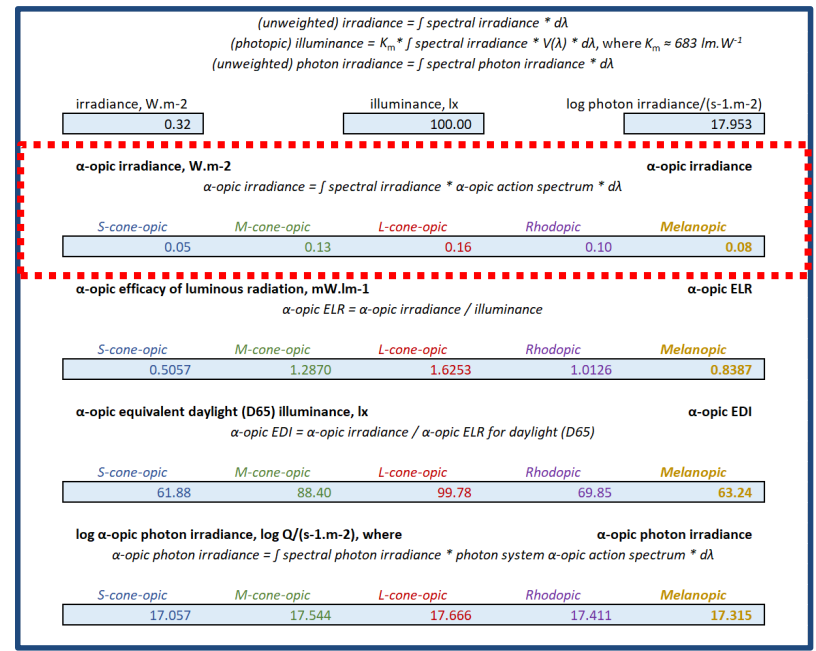

$\alpha$-opic irradiance, w.m-2

$\alpha$-opic irradiance

$\alpha$-opic irradiance $=\int$ spectral irradiance ${ }^{*} \alpha$-opic action spectrum $* d \lambda$ 


\section{Example calculation - Melanopic irradiance}
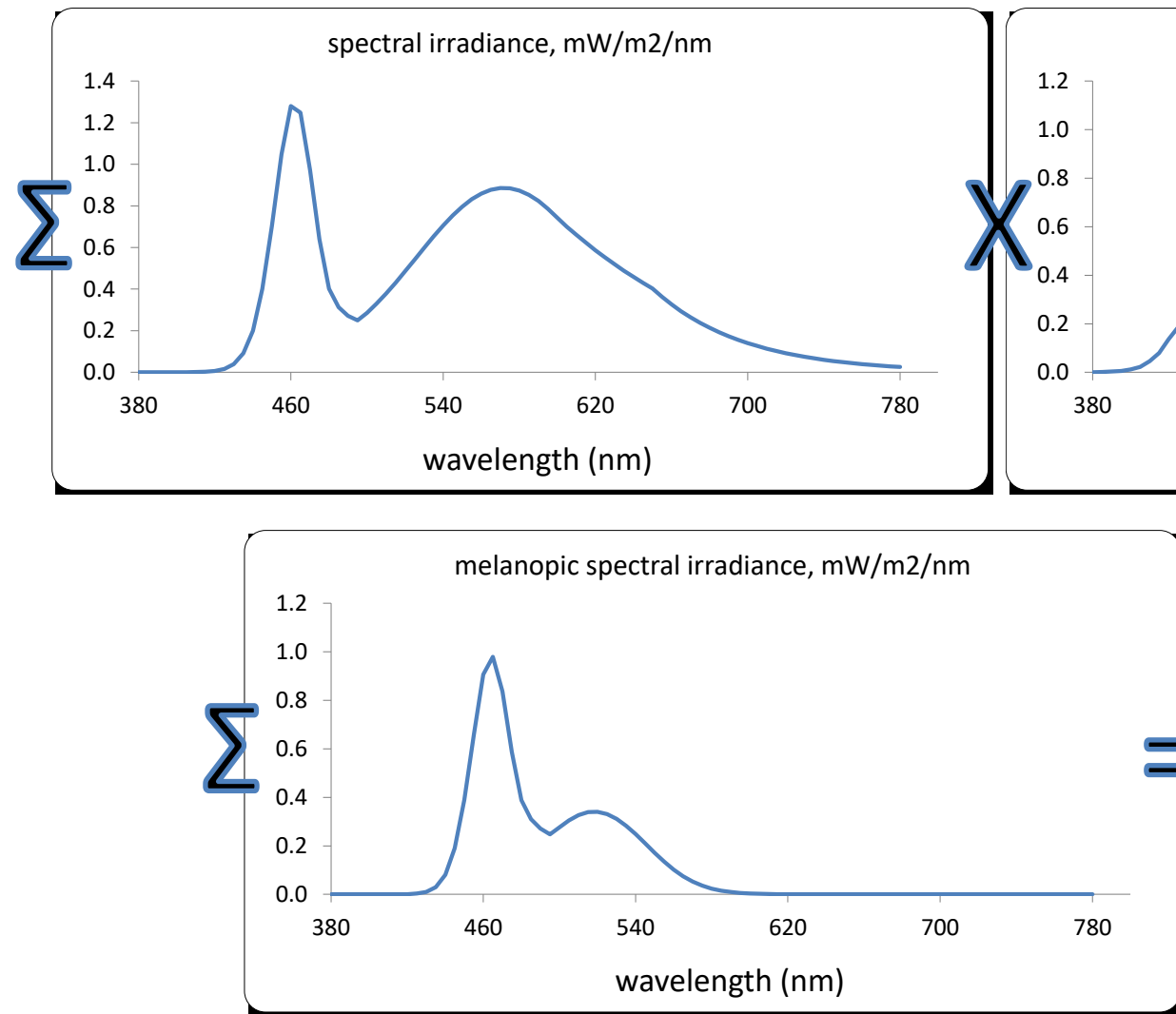

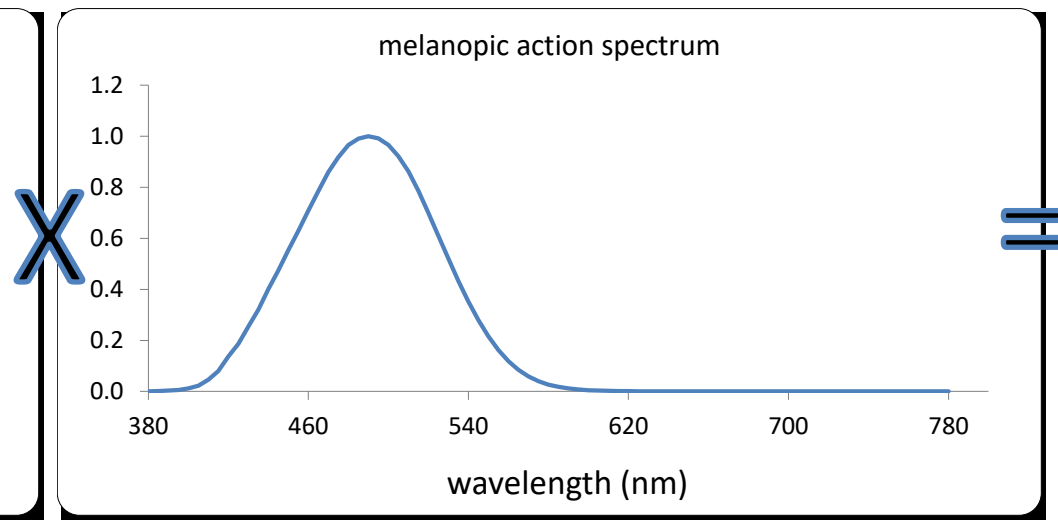

$83.9 \mathrm{~mW} \cdot \mathrm{m}^{-2}$, or $0.08 \mathrm{~W} \cdot \mathrm{m}^{-2}$ as shown on p. 11 


\section{Outputs - a-opic ELR}

\section{$E L R=$ Efficacy of Luminous Radiation}

$$
K_{\alpha, \mathrm{v}}=E_{\alpha} / E_{\mathrm{v}}
$$

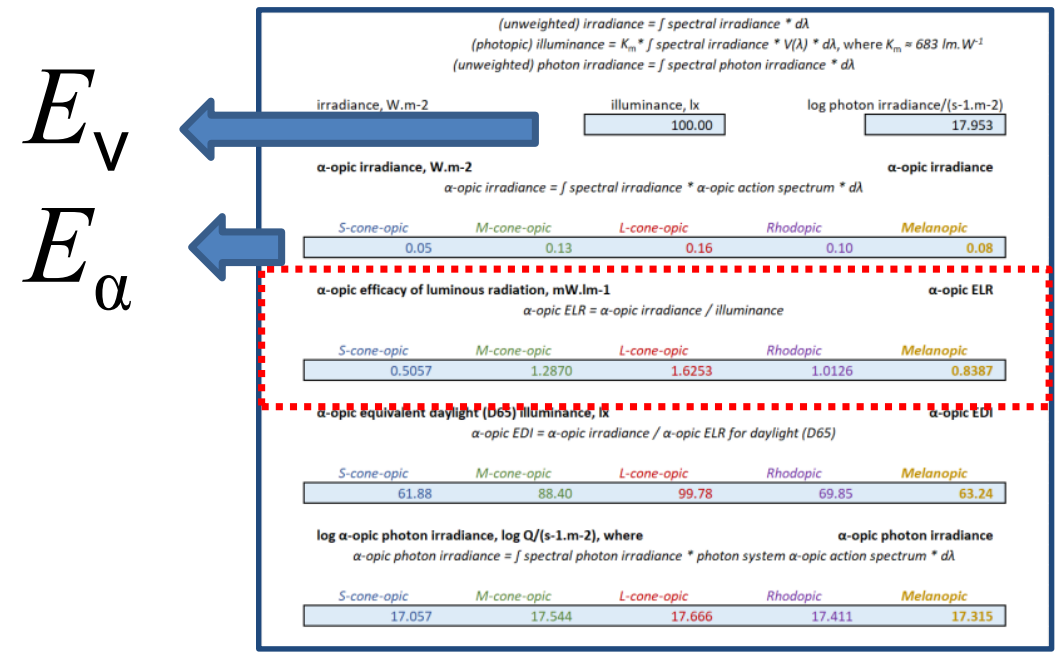




\section{Outputs - $\alpha$-opic EDI}

\section{$\mathrm{EDI}=$ Equivalent Daylight (D65) Illuminance}

"illuminance, produced by radiation conforming to standard daylight (D65), that provides

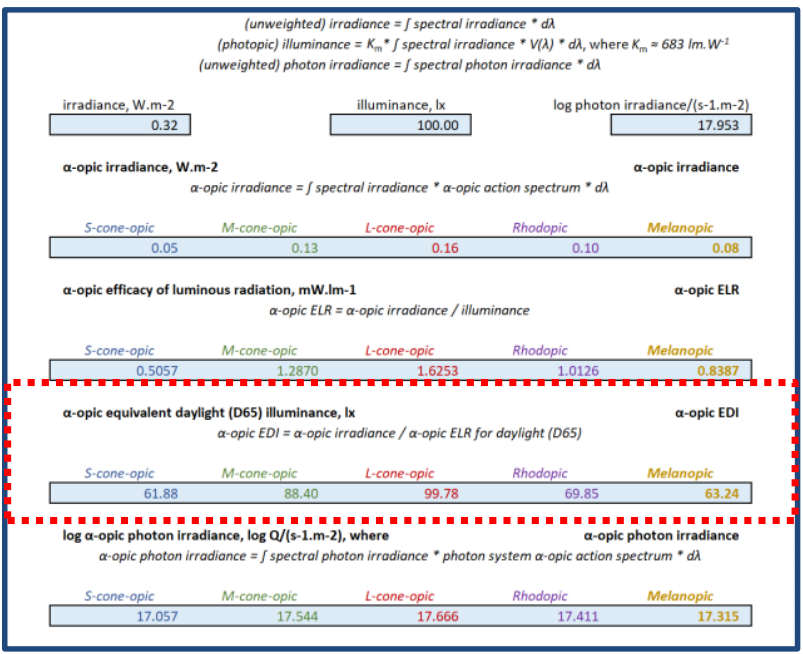

an equal $\alpha$-opic irradiance as the test source" 


\section{Outputs - $\alpha$-opic EDI calculation method}

\section{$E D I=$ Equivalent Daylight (D65)

$$
E_{\mathrm{v}, \alpha}^{\mathrm{D} 65}=E_{\alpha} / K_{\alpha, \mathrm{v}}^{\mathrm{D} 65}
$$ Illuminance

$$
\text { since } K_{\alpha, \mathrm{v}}=E_{\alpha} / E_{\mathrm{v}}
$$

"illuminance, produced by radiation conforming to standard daylight (D65), that provides an equal $\alpha$-opic irradiance as the test source"

$$
K_{\alpha, v}^{\mathrm{D} 65} \text { are five fixed values }
$$

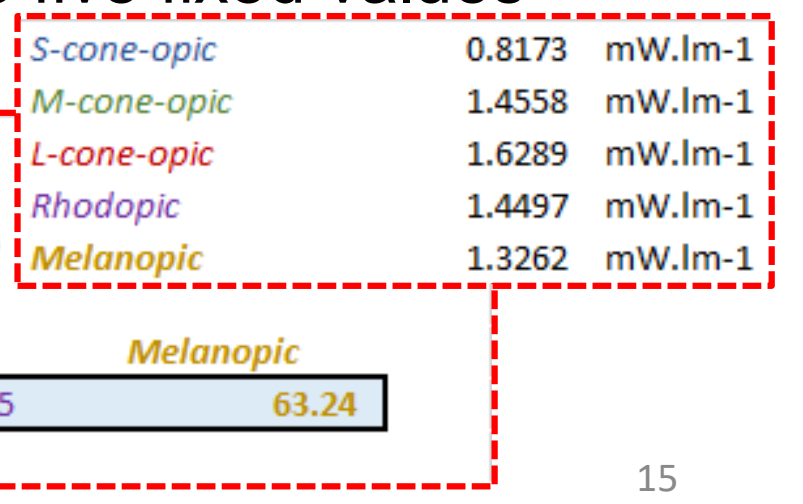




\section{Example calculation - Melanopic equivalent daylight (D65) illuminance}
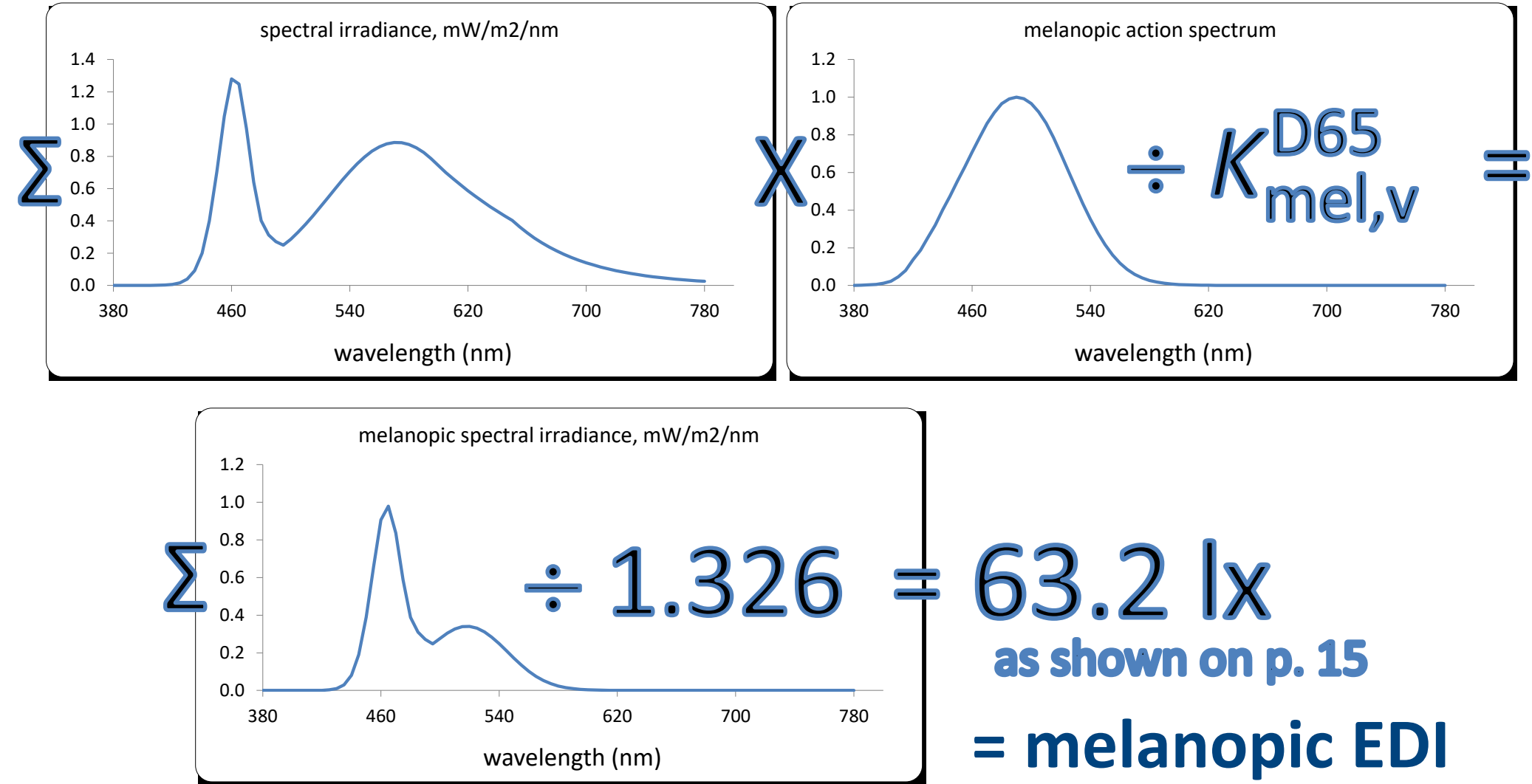


\section{Example calculations - Summary}

melanopic irradiance

$$
\div
$$

melanopic

$$
\text { ELR }
$$$$
1.326 \mathrm{~mW} \cdot \mathrm{Im}^{-1}
$$$$
=
$$

melanopic

EDI

$$
83.9 \mathrm{~mW} \cdot \mathrm{m}^{-2}
$$$$
\div
$$$$
=
$$

$63.2 \mathrm{~lx}$
$1 \mathrm{~mW} \cdot \mathrm{m}^{-2}$

$$
\div
$$

$1 \mathrm{~mW} \cdot \mid \mathrm{m}^{-1}$

$=$

$1 \mathrm{~lm} \cdot \mathrm{m}^{-2}$

$=$

$1 \mathrm{~lx}$ 


\section{Outputs $-\alpha$-opic photon irradiance}

\section{$E_{\mathrm{p}, \alpha}\left(\right.$ in s s-1. $\left.^{-2}\right)$}

"effective photobiological photon irradiance with the spectral photon irradiance, $E_{\mathrm{p}, \lambda}(\lambda)$ (or number of photons per second per square metre), spectrally weighted with the $\alpha$-opic action spectrum $s_{\mathrm{p}, \mathrm{a}}(\lambda)^{\prime \prime}$

Each value is presented as the logarithm to base $10\left(\log _{10}\right)$ of the $\alpha$-opic photon irradiance, $Q$, divided by $1 \mathrm{~s}^{-1} \cdot \mathrm{m}^{-2}$.

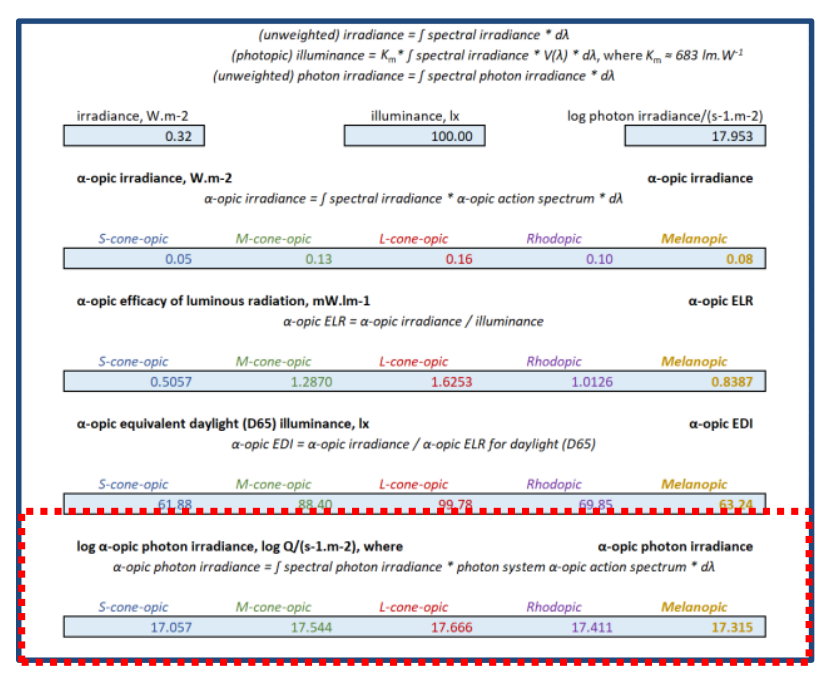

$\log \alpha$-opic photon irradiance, $\log \mathrm{Q} /(\mathrm{s}-1 . \mathrm{m}-2)$, where

$\boldsymbol{\alpha}$-opic photon irradiance $\alpha$-opic photon irradiance $=\int$ spectral photon irradiance $*$ photon system $\alpha$-opic action spectrum $* d \lambda$

S-cone-opic

M-cone-opic

L-cone-opic

Rhodopic

Melanopic

17.544

17.666

17.411

17.315 


\section{Photon irradiance in standard notation}

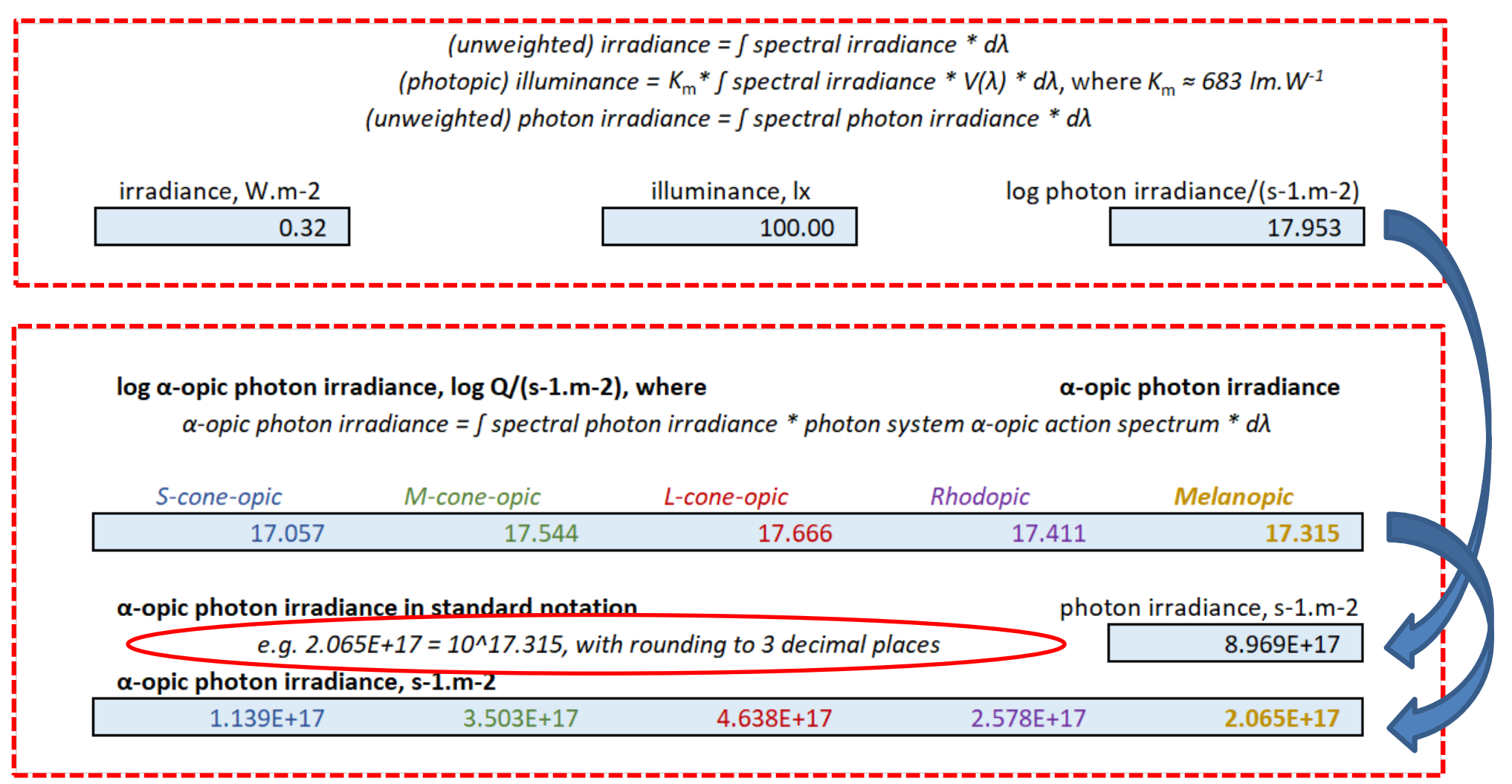




\section{Inputs - User-defined spectrum (1)}

User

\section{Example for user spectra}

\section{First enter a title}

< User defined spectrum 001 >

1. Select 'User' from list

$$
<\text { User > }
$$

2. Select spectral quantity (4 options*) < irradiance > and units

(SI prefixes) $\quad\langle\mu>\langle\mathrm{c}\rangle$

* luminance and illuminance are not supported as spectral inputs

\section{CIE S $026 \alpha$-opic Toolbox}

Inputs sheet

Inputs = blue

User-defined spectrum 001

1. Select source of spectral data Spectrum

User

2. Select measurement details Spectral quantity, $\mathrm{Q}$ Main SI prefix Area prefix irradiance

$\mu$ c irradiance

photon radiance photon irradiance radiance irradiance

tuminance-*

Huminance- ${ }^{*}$

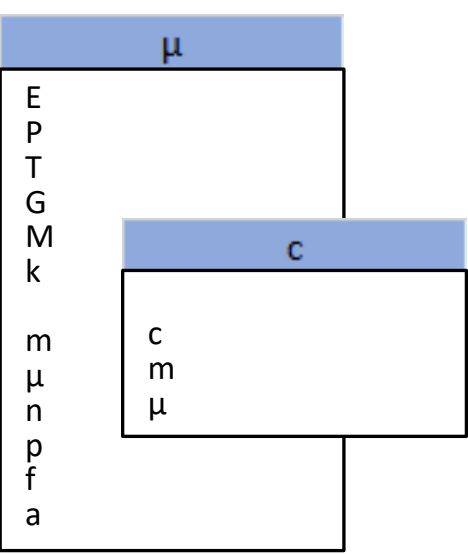




\section{Inputs - User-defined spectrum (2)}

2. Select spectral quantity

(4 options)

$<$ irradiance > and units

(SI prefixes)

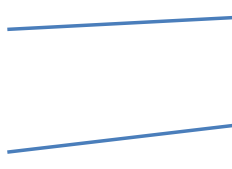
$<\mu>\langle c\rangle$

3. Clear this input

4. Enter resolution

$(1 \mathrm{~nm}, 2 \mathrm{~nm}, 4 \mathrm{~nm}$ or $5 \mathrm{~nm})<2>$

5. Enter spectral data (380 $\mathrm{nm}$ to $780 \mathrm{~nm}$ )

Finally clear any data below the row for $780 \mathrm{~nm}$.

2. Select measurement details Spectral quantity, $\mathrm{a}$ irradiance Main SI prefix Areaprefix

3. Skip this step

Clear this input

4. Select wavelength step

Step size, $\mathrm{nm}$

2

5. Enter spectral irradiance data

\begin{tabular}{l|l}
$\mathrm{nm}$ & $\mu \mathrm{W} . \mathrm{cm}-2 . \mathrm{nm}-1$ \\
380 & 1.000 \\
382 & 1.000 \\
384 & 1.000 \\
386 & 1.000 \\
388 & 1.000 \\
390 & 1.000 \\
392 & 1.000
\end{tabular}

The spectral quantity, units and the resolution of the spectral data in step 5 depend on steps 2 and 4 , as indicated by the arrows. 


\section{Charts - Spectra and $\alpha$-opic weightings}
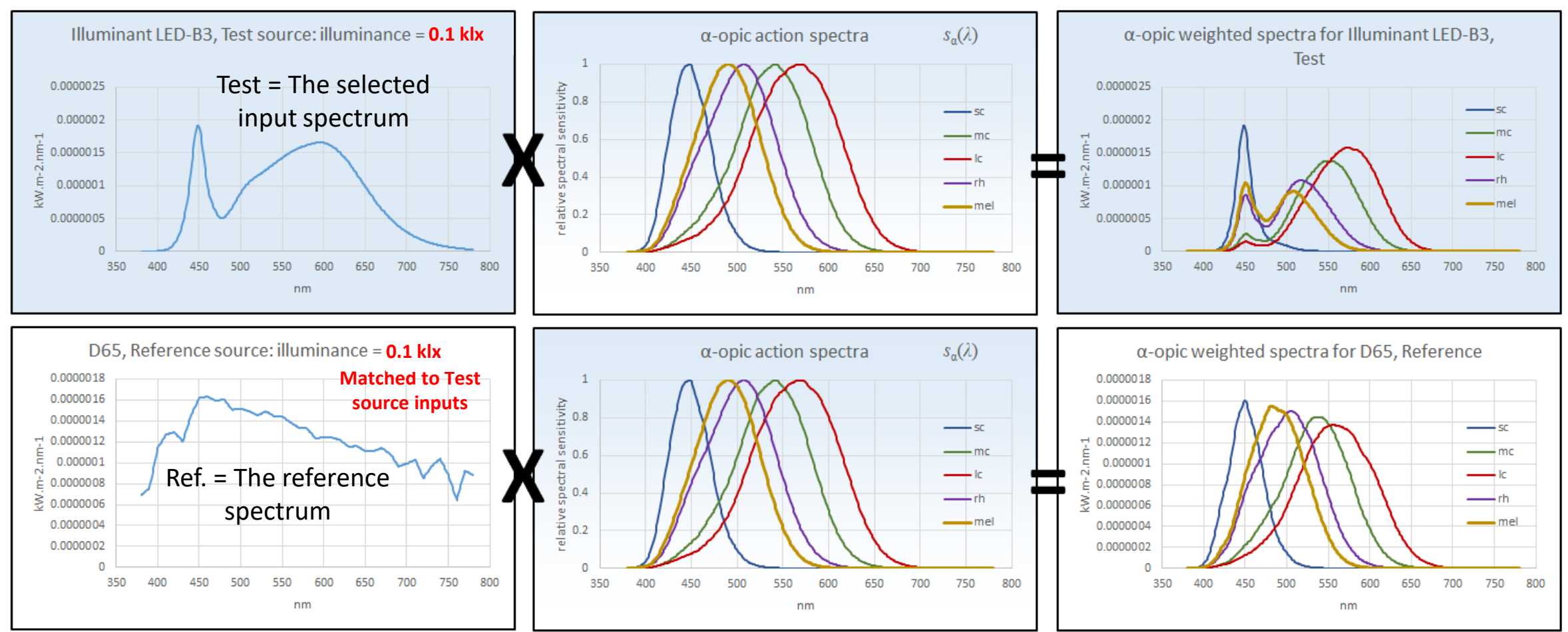

The input data is called the Test source. The default CIE S 026 Reference source is daylight (D65); Lucas et al., 2014 uses equi-energy (E).

The units used on the $\mathrm{y}$-axis depend on the prefixes selected in Inputs cells $\mathrm{C} 12$ and $\mathrm{C} 13$. The units used in the chart titles depend on the prefixes selected in Advanced Outputs cells $\mathrm{H} 10$ and $\mathrm{H} 11$. 


\section{Glossary (see References, page 29, for further information)}

List of quantities, abbreviations and symbols

Previously published (CIE DIS 017:2016; CIE 018:2019)

$E_{\mathrm{v}}=$ (photopic) illuminance; $L_{\mathrm{v}}=$ (photopic) luminance

$E=E_{\mathrm{e}}=$ irradiance (i.e. unweighted); $L=L_{\mathrm{e}}=$ radiance (i.e. unweighted)

$E_{\mathrm{p}}=$ photon irradiance (i.e. unweighted); $L_{\mathrm{p}}=$ photon radiance (i.e. unweighted)

From CIE S 026:2018

$\alpha$-opic $(\alpha)$ may represent any one of S-cone-opic (sc), M-cone-opic (mc), L-cone-opic (Ic), rhodopic (rh) and melanopic (mel)

$s_{\alpha}(\lambda)=s_{e, \alpha}(\lambda)=\alpha$-opic spectral weighting function (action spectrum)

$K_{\alpha, v}=\alpha$-opic efficacy of luminous radiation, $\alpha$-opic ELR

$K^{\mathrm{D} 65}{ }_{\alpha, \mathrm{v}}=\alpha$-opic ELR for daylight (D65)

$\gamma^{\mathrm{D} 65}{ }_{\alpha, \mathrm{v}}=\alpha$-opic daylight (D65) efficacy ratio, $\boldsymbol{\alpha}$-opic DER

$E_{\alpha}=E_{\mathrm{e}, \alpha}=\alpha$-opicirradiance (i.e. weighted by $s_{\alpha}(\lambda)$ )

$E_{\mathrm{v}, \alpha}^{\mathrm{D}}=\alpha$-opic equivalent daylight (D65) illuminance, $\alpha$-opic EDI

$L_{\alpha}=L_{e, \alpha}=\alpha$-opic radiance (i.e. weighted by $s_{\alpha}(\lambda)$ )

$L^{\mathrm{D} 65}{ }_{\mathrm{v}, \alpha}=\alpha$-opic equivalent daylight (D65) luminance, $\alpha$-opic EDL

\section{From CIE S 026:2018 and 9th edition of SI Brochure}

$s_{p, \alpha}(\lambda)=\alpha$-opic spectral weighting function (action spectrum) in the photon system (renormalised to maximum of 1 )

$E_{\mathrm{p}, \alpha}=\alpha$-opic photon irradiance (i.e. weighted by $s_{\mathrm{p}, \alpha}(\lambda)$ )

$L_{p, \alpha}=\alpha$-opic photon radiance (i.e. weighted by $s_{p, \alpha}(\lambda)$ )

Further $\alpha$-opic quantities and their symbols can be derived, e.g. $\alpha$-opic equivalent daylight (D65) luminous flux, $\Phi_{\mathrm{v}, \alpha}^{\mathrm{D} 65}$.

However, any other abbreviations, e.g. " $\alpha$-opic EDLF" may be ambiguous, and should be avoided.

Due to prior publications, the subscript order for ELR and DER differs from $\alpha$-opic equivalent daylight (D65) quantities. 


\section{Advanced Outputs - Output mode selection}
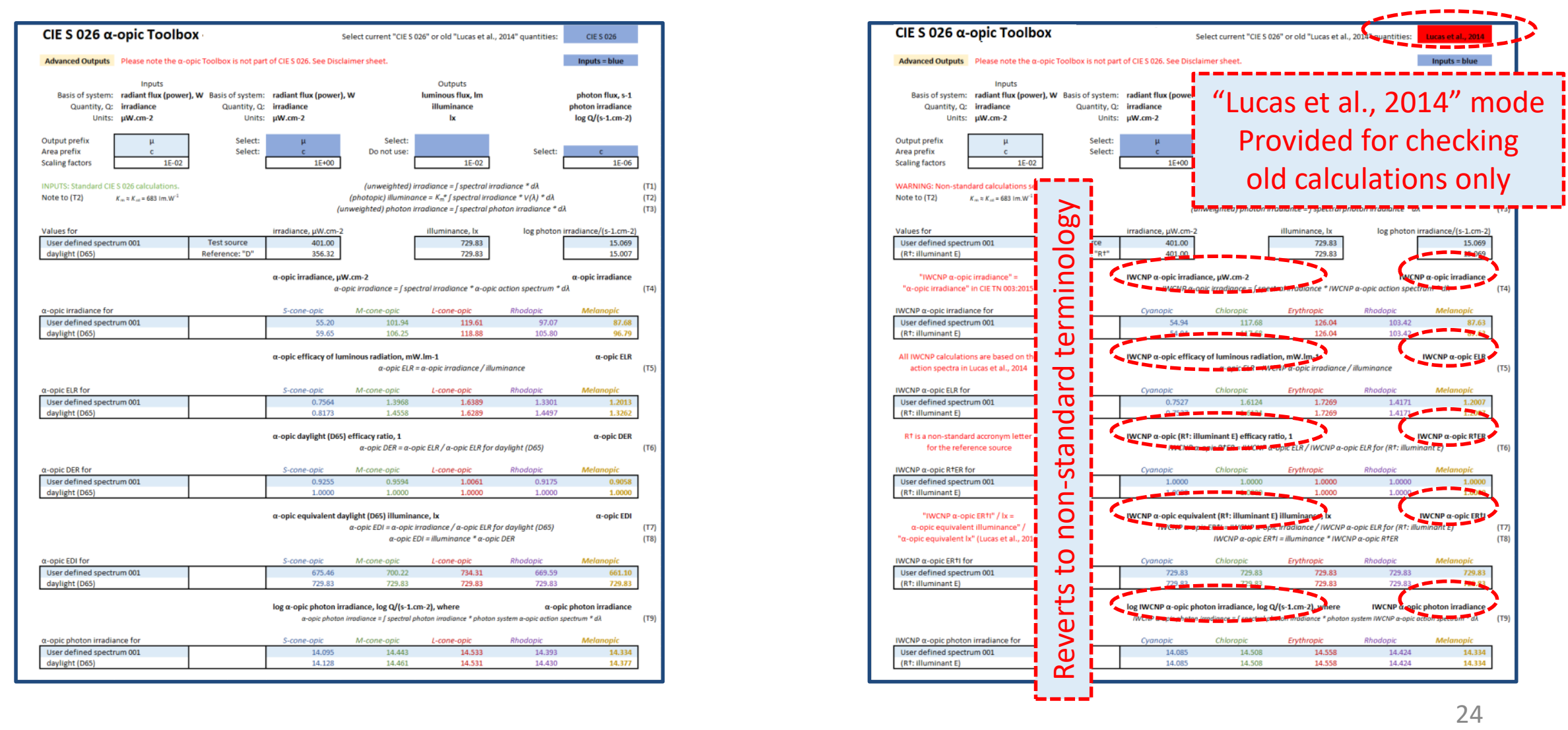


\section{Advanced Outputs - Daylight efficacy ratio (DER)}

" $\alpha$-opic daylight (D65) efficacy ratio, <for a source>"

$\gamma_{\alpha, \mathrm{v}}^{\mathrm{D} 65} \quad$ where $\gamma_{\alpha, \mathrm{v}}^{\mathrm{D} 65}=K_{\alpha, \mathrm{v}} / K_{\alpha, \mathrm{v}}^{\mathrm{D} 65}$

Converts illuminance, $E_{\mathrm{v}}$, to $\alpha$-opic EDI:

$$
E_{\mathrm{v}, \alpha}^{\mathrm{D} 65}=E_{\mathrm{v}} \cdot \gamma_{\alpha, \mathrm{v}}^{\mathrm{D} 65}
$$

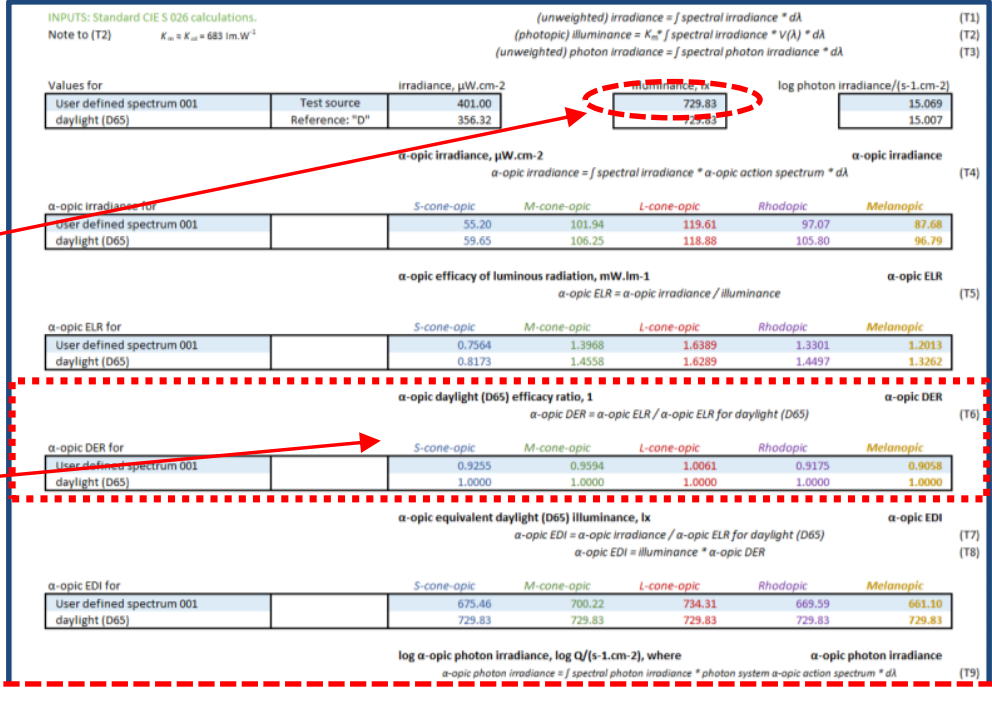

$\alpha$-opic DER $=\alpha$-opic ELR $/ \alpha$-opic ELR for daylight (D65)

S-cone-opic

M-cone-opic

0.9256

1.0000

L-cone-opic

Rhodopic

Melanopic 


\section{Advanced Outputs - Reference source values}

\section{Reference source values are shown matched to the input for the test source}

Reference source (automatic) $=$

Daylight (D65) for CIE S 026 mode

Equi-energy (E) for Lucas et al., 2014 mode

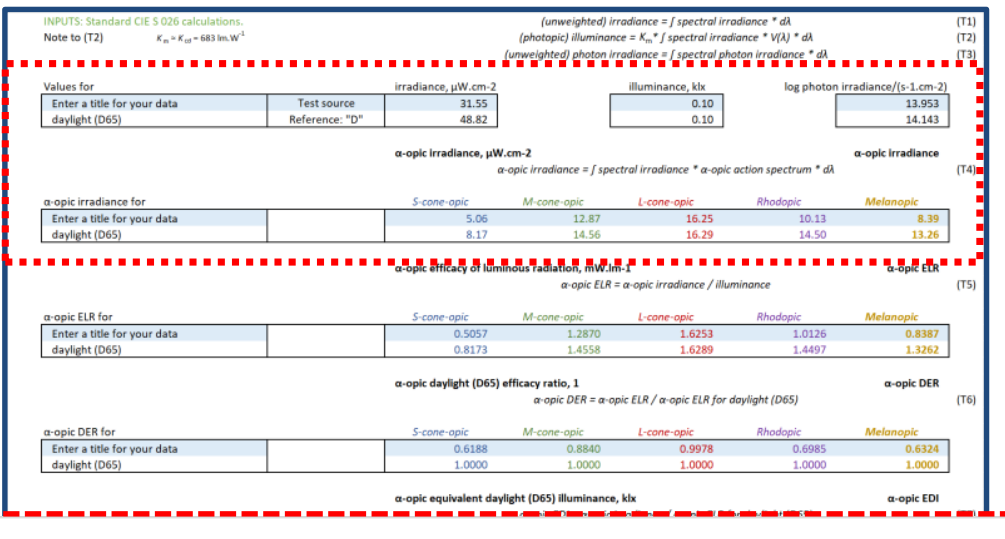

Values for

User defined spectrum 001 daylight (D65) irradiance, $\mu \mathrm{W} . \mathrm{cm}-2$

\begin{tabular}{c|c|c|}
\multicolumn{2}{c}{ irradiance, $\mu \mathrm{W} . \mathrm{cm}-2$} \\
Rest source & 402.00 \\
\hline
\end{tabular}

$\alpha$-opic irradiance, $\mu \mathrm{W} . \mathrm{cm}-2$ illuminance, $\mathrm{dx}$

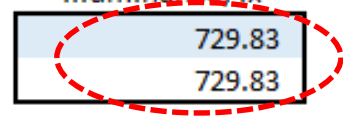

log photon irradiance/[s-1.cm-2]

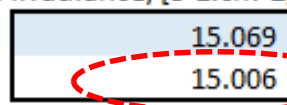

$\alpha$-opic irradiance

$\alpha$-opic irradiance $=\int$ spectral irradiance $* \alpha$-opic action spectrum ${ }^{*} d \lambda$ 


\section{Advanced Outputs - Output prefix options}

The user can choose the output prefixes that determine the units used in the output fields below.

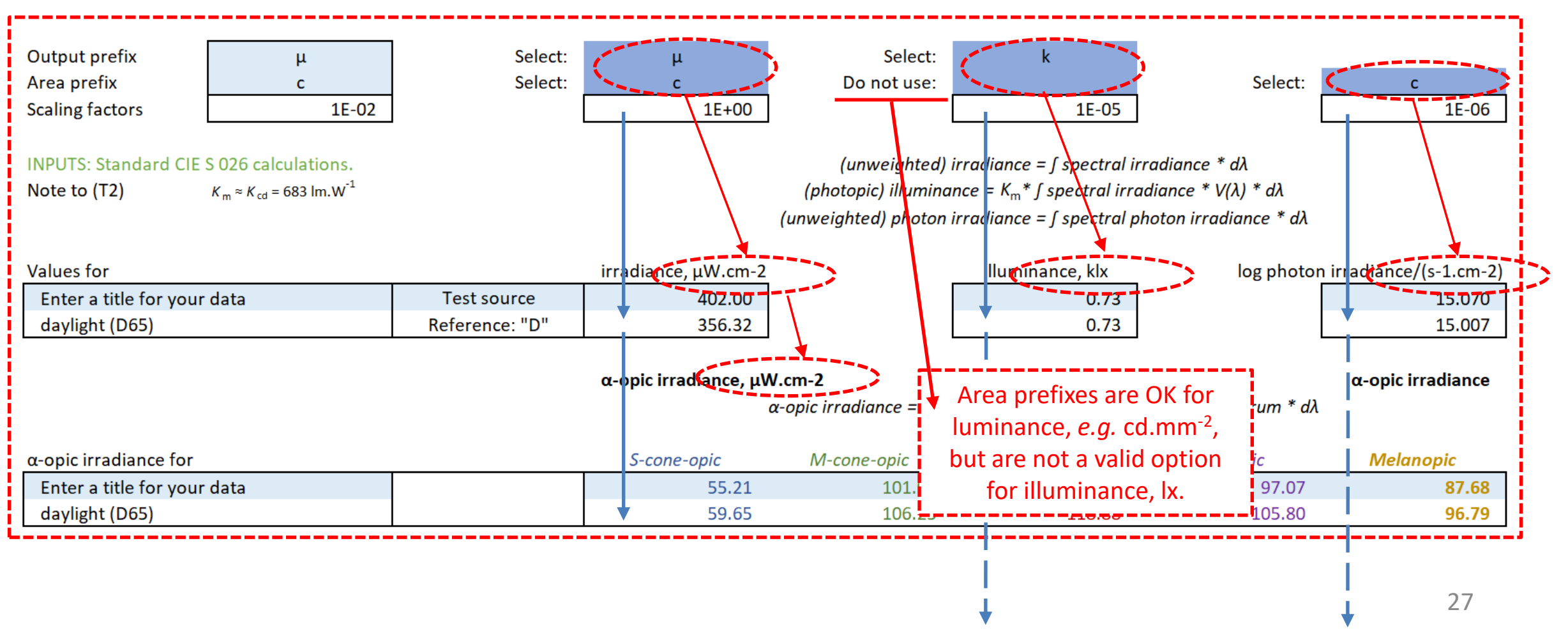




\section{IT-related issues and features}

1. The $\alpha$-opic Toolbox is deliberately designed without macros or range names, meaning that it can be integrated with other spreadsheets (including your own macros if you should wish).

2. So if you have trouble pasting spectral data into Inputs (reported on some platforms), try adding a blank sheet for pasting and link the Inputs to the cells containing your data on this new sheet.

3. Excel expects you to enter numerical data using the regional number format settings on your system. This applies to how you write numbers with decimals, for example " 0,1 " vs " 0.1 ".

4. Unused cells should be cleared of all contents, including those in the spectral data (Inputs, cells C24:C424). The error messages in red text should alert you to when this has not been completed.

5. The SI prefix dropdown boxes temporarily interpret " $m$ " as " $M$ ". However, provided you choose the option you want, this has no further impact, and the calculations will always match the case of the prefix as shown on the Inputs sheet (and Advanced Output sheet) after entry.

6. The Chart titles' units are linked to cells $\mathrm{H} 10: \mathrm{H} 11$ of the Advanced Outputs sheet; the $\mathrm{y}$-axis and the Chart $\mathrm{y}$-axes' units are linked to cells $\mathrm{C} 12: \mathrm{C} 13$ of the Inputs sheet.

7. Always subject your calculations to sense-checking and manual spot-checking, based on the data and definitions in CIE S 026:2018. Please avoid re-using a user-modified Toolbox (see 1.-2. above). 


\section{References}

BIPM, 2019. Bureau International des Poids et Mesures: The International System of Units (SI), $9^{\text {th }}$ edition. BIPM, Sèvres.

CIE, 2011. CIE S 017:2011. ILV: International Lighting Vocabulary. CIE, Vienna.

CIE, 2016. CIE DIS 017:2016. ILV: International Lighting Vocabulary, $2^{\text {nd }}$ edition. CIE, Vienna.

CIE, 2018a. CIE 015:2018. Colorimetry, 4th edition. CIE, Vienna.

CIE, 2018b. CIE S 026:2018. System for Metrology of Optical Radiation for ipRGC-Influenced Responses to Light. CIE, Vienna.

CIE, 2019. CIE 018:2019 The Basis of Physical Photometry, $3^{\text {rd }}$ edition. CIE, Vienna.

Lucas, R.J., Peirson, S.N., Berson, D.M., Brown, T.M., Cooper, H.M., Czeisler, C.A., Figueiro, M.G., Gamlin, P.D., Lockley, S.W., O’Hagan, J.B., Price, L.L., Provencio, I., Skene, D.J. \& G.C. Brainard, 2014. Measuring and using light in the melanopsin age. Trends in neurosciences, 37(1), 1-9. 